\title{
Conocimientos y valoraciones de estudiantes de bachillerato sobre la utilización de aplicaciones biotecnológicas
}

\author{
Cristina Ruiz González (D), Luisa López-Banet (iD y Enrique Ayuso Fernández (D) \\ Departamento de Didáctica de las Ciencias Experimentales. Facultad de Educación. Universidad de Murcia. \\ cristina.ruiz8@um.es,llopezbanet@um.es,ayuso@um.es
}

[Recibido: 19 noviembre 2019. Revisado: 27 marzo 2020. Aceptado: 23 julio 2020]

Resumen: El aumento de la utilización de las aplicaciones de biotecnología está suponiendo una mayor presencia de la misma en los currículos de Biología en la ESO y Bachillerato y, en consecuencia, también de las investigaciones acerca de los problemas de enseñanza y aprendizaje relacionados. Así, en este trabajo se pretende mostrar cuáles son los conocimientos y las valoraciones de estudiantes de $2^{\circ}$ de Bachillerato sobre las aplicaciones en biotecnología, y más en concreto, sobre la biofarmacología. El análisis de los cuestionarios y las entrevistas individuales han permitido reflejar los criterios que utilizan durante la justificación de sus puntos de vista, analizando aspectos tanto de contenido como de tipo estructural, para facilitar la comprensión de sus decisiones. Además, en nuestro trabajo constatamos que las dificultades sobre conocimientos básicos en áreas como la genética o la microbiología pueden dificultar la comprensión de la biotecnología. Por otra parte, nuestro alumnado se muestra más favorable hacia las aplicaciones orientadas a la resolución de problemas de salud, o las que no requieren animales en la investigación. Finalmente, consideramos conveniente la utilización en el aula de controversias sociocientíficas basadas en contextos reales para conseguir un mayor grado de implicación del alumnado en actividades de argumentación. Para ello, planteamos una propuesta didáctica, sobre la fabricación de insulina para personas diabéticas, que puede servir de referente para el profesorado de Bachillerato.

Palabras clave: actitud, argumentación, Bachillerato, biofarmacología, conocimiento, formación del profesorado.

\section{Knowledge and assessments of bachelor's students on the use of biotechnological applications}

Abstract: The increased use of biotechnology applications is leading to a greater presence of them in Biology curricula in ESO and Baccalaureate. Consequently, it also can be found an increment in educational researches related to their teaching and learning. Thus, the aim of this work is to assess the knowledge and values of 2 nd Baccalaureate students about applications in biotechnology and, specifically, about biopharmacology. The analysis of the questionnaires and the individual interviews has targeted towards both the content and the structure of the claims that students reveal. The criteria that they use during the justification of their points of view facilitate the understanding of their decisions. Furthermore, in our work we find that difficulties regarding basic knowledge in areas such as genetics or microbiology can hinder the understanding of biotechnology. On the other hand, our students are more favorable towards applications aimed at solving health problems, or those that do not require animals in research. Finally, we consider it convenient to use socio-scientific controversies based on real contexts in the classroom to achieve a greater degree of student involvement in argumentation practices. To do this, we propose a teaching activity based on the manufacture of insulin for diabetics, which can serve as a reference for teachers of Baccalaureate.

Keywords: attitude, argumentattion, Baccalaureate, biopharmacology, knowledge, teacher training.

Para citar este artículo: Ruiz C., López-Banet L. y Ayuso E. (2021) Conocimientos y valoraciones de estudiantes de bachillerato sobre la utilización de aplicaciones biotecnológicas. Revista Eureka sobre Enseñanza y Divulgación de las Ciencias 18(1), 1102. doi: 10.25267/Rev_Eureka_ensen_divulg_cienc.2021.v18.i1.1102

\section{Introducción}

La biotecnología puede definirse como la aplicación de la ciencia y la tecnología a los organismos vivos (o a partes, productos o modelos de estos) con el fin de alterar materiales vivos o inertes para la producción de conocimientos, bienes y servicios (OCDE 2005). En el momento actual, es un área en constante crecimiento que genera un conocimiento de gran 
valor, al mismo tiempo que está inmersa en algunas controversias sociocientíficas sobre el uso de sus aplicaciones. Estos aspectos motivan que el alumnado no solo deba conocer sus principios biológicos, sino también que sea consciente de los valores que están relacionados con ella, así como los posibles beneficios y riesgos de carácter político, social, legal y ético que derivan de su desarrollo (Hammann 2018). Una de las ramas de la biotecnología que más se está desarrollando en la actualidad es la llamada biotecnología roja, médica o farmacéutica (Kafarski 2012). Sus aplicaciones se centran en el cuidado de la salud, como la producción de vacunas y antibióticos, el descubrimiento de nuevos medicamentos, terapias regenerativas, construcción de órganos artificiales y nuevos diagnósticos. El posicionamiento a favor o en contra de la utilización de estas aplicaciones puede conducir a importantes controversias sociocientíficas (CSC).

Con respecto a las CSC existe cierto consenso en la Didáctica de las Ciencias de que su uso debe trasladarse a las aulas, ya que generan situaciones problemáticas reales que van a demandar competencias como el análisis crítico, el razonamiento y la argumentación, que son necesarias para la formación de estudiantes de Educación Secundaria (Domènech-Casal 2017). Además, tales CSC pueden jugar un papel destacado para favorecer la toma de decisiones sobre las mismas y propiciar, al mismo tiempo, la alfabetización científica y el desarrollo del razonamiento entre el alumnado (Jiménez-Aleixandre y Erduran 2007, Maguregi, Uskola y Burgoa 2017). Por otra parte, son de gran utilidad los trabajos que abordan la argumentación en las aulas. Recordemos que ésta puede definirse como la evaluación de enunciados de conocimiento a partir de las pruebas disponibles para contribuir a aprender a aprender, al hacer públicos procesos de razonamiento, que generalmente son privados, y comprender aspectos esenciales de la naturaleza de la ciencia, como la justificación de los conocimientos con pruebas (Jiménez-Aleixandre y Puig 2013). Un argumento es, en este sentido, el resultado de coordinar una conclusión con las pruebas que la apoyan y está formado por tres elementos esenciales: conclusión, prueba y justificación (Jiménez-Aleixandre y Puig 2013).

En este aspecto, la utilización en el aula de CSC basadas en la utilización de aplicaciones biotecnológicas, se convierte en una herramienta de gran utilidad para el desarrollo de las destrezas implicadas en la argumentación en el aula, lo que podrá mejorar la participación en debates sociales (Simonneaux 2002). Además, tiene lugar una intensificación del razonamiento del alumnado cuando este tipo de actividades de aula se presenta en un contexto auténtico, como podría ser el uso de la terapia génica, especialmente si esta autenticidad, además, permite difundir adecuadamente la imagen sobre la ciencia, los científicos y la actividad científica (Simonneaux y Chouchane 2011).

\section{Contexto y objetivos de la investigación}

La argumentación de los y las estudiantes sobre sus posiciones ante situaciones problemáticas hacia el uso de la biotecnología, así como su actitud, se puede ver influenciada por sus conocimientos y valoraciones que hacen de la misma, como se describe en este apartado.

\section{Qué se ha investigado sobre los conocimientos en biotecnología en diferentes edades}

El conocimiento sobre biotecnología ha sido definido consistentemente como insuficiente y erróneo por diferentes autores, tal y como muestra la bibliografía revisada. Según Dawson (2007), estudiantes de 12 a 17 años no tienen conocimiento científico sobre la biotecnología o la ingeniería genética o no saben distinguir entre usos potenciales o reales de la biotecnología. Igualmente, Ruiz, Banet y López-Banet (2017a) y Chen, Chu, Lin y Chiang (2016) destacan que estudiantes de 15-18 años son capaces de citar muy pocas aplicaciones de la biotecnología. En relación a los alimentos transgénicos, estudiantes universitarios de 18 a 25 años de edad (Prokop, Lesková, Kubiatko y Diran 2007), tanto de instituto como universitarios (Usak, 
Erdogan, Prokop y Ozel 2009), tienen dudas acerca de si los alimentos transgénicos pueden contener sustancias químicas peligrosas o cambiar el $\mathrm{ADN}$ de las células de quienes los consumen. Poniendo el foco en el ámbito sanitario, diferentes estudios muestran que el alumnado entre 17 y 18 años tiene conocimientos sobre la producción de medicamentos y vacunas mediante biotecnología (Fonseca, Costa, Lencastre y Tavares 2012) y que estudiantes universitarios conocen el uso de organismos modificados genéticamente en medicina. Sin embargo, se aprecia un conocimiento superficial y, a menudo, incorrecto de los procesos biotecnológicos (Öztürk-Akar 2016).

\section{Qué se ha investigado sobre la actitud hacia la biotecnología en el ámbito de la salud}

En relación con las aplicaciones en medicina, la mayor parte de los trabajos sugieren que el alumnado tiene una actitud favorable hacia el uso de organismos modificados genéticamente (Öztürk-Akar 2016), la producción de nuevos medicamentos, el diagnóstico y/o tratamiento de enfermedades (Occelli, Vilar y Valeiras 2011), la terapia génica y las aplicaciones clásicas (Fonseca et al. 2012). A esta predisposición favorable, Sáez, Gómez-Niño y Carretero (2008) la denominan "máximo de la salud" ya que esta finalidad médica justificaría cualquier tipo de intervención tecnológica. De la Vega, Lorca y de las Heras (2018) señalan, además, que existe un alto nivel de opiniones a favor del uso de microorganismos en biotecnología; sin embargo, el alumnado es más reacio a emplear en las investigaciones otros seres vivos, como los vegetales, y muestra un claro rechazo al uso experimental de animales. No obstante, metaanálisis como el de Gardner y Troelstrup (2015) consideran que no se ha ido más allá de estudios descriptivos sobre la actitud hacia la tecnología genética y que los trabajos deben ser analizados dentro de su contexto cultural y educativo particular y dentro de un marco de análisis consensuado.

\section{La argumentación en el aula y por qué evaluarla}

Como se ha señalado, numerosos trabajos han puesto de manifiesto la importancia de incluir la argumentación en las aulas de ciencias para discutir temas científicos, relacionar datos y ofrecer explicaciones; si bien, la capacidad de desarrollar argumentos no suele ser un elemento habitual en nuestro sistema escolar (Jiménez-Aleixandre, Bugallo y Duschl 2000; Bravo y Jiménez-Aleixandre 2014).

En los últimos 30 años, la biotecnología ha experimentado un rápido desarrollo tanto en cuestiones científicas y económicas, como en las relacionadas con la salud, los alimentos modificados genéticamente o el medioambiente; pero también ha aumentado la conciencia pública sobre las dudas que rodean a varias de las aplicaciones biotecnológicas. De acuerdo con Christenson (2015), la enseñanza de las ciencias no solo tiene que centrarse en los contenidos de la materia, sino también en una estrategia de enseñanza, que incluye el discurso y el uso social de la ciencia, como es la argumentación de CSC. Por ello, resulta de interés que nos preguntemos cómo justifica el alumnado sus posiciones sobre aspectos relacionados con las aplicaciones biotecnológicas, para desarrollar estrategias que podrían ser utilizadas por el profesorado para evaluar la calidad de las argumentaciones. Una manera de abordar el análisis de argumentaciones es la codificación de las declaraciones realizadas utilizando el programa de análisis cualitativo Atlas.ti (Martínez-Chico, Jiménez-Liso, López-Gay y Lucio-Villegas 2014).

Muchas investigaciones sobre evaluación de argumentaciones utilizan como referencia el marco propuesto por Toulmin (2003), conocido como "Patrón de Argumentación" (TAP), para analizar la calidad de un argumento, en función de la presencia o ausencia de los componentes estructurales que lo conforman (afirmaciones, datos, garantías, respaldos, calificadores y refutaciones). Varios investigadores han adaptado el TAP de diferentes maneras para facilitar los análisis. Algunas contribuciones han considerado que el modelo de análisis de 
los argumentos debe tener en cuenta tanto el contenido de la argumentación (la adecuación o exactitud de los componentes en el argumento desde una perspectiva científica), como la estructura de la misma (los componentes del argumento) (Chang y Chiu 2008). Otros estudios vienen considerando un argumento de calidad como aquel que consigue alcanzar simultáneamente elevados niveles de coherencia y complejidad estructural (Martínez-Bernat, García-Ferrandis y García-Gómez 2019).

Desde otra perspectiva, algunos trabajos han investigado la argumentación del alumnado sobre aplicaciones biotecnológicas, no tanto para proporcionar criterios que evalúen la calidad de la argumentación, sino para analizar en qué valores se sustentan los argumentos, según la importancia relativa que les atribuyen, y cómo afectan estos valores a la toma de decisiones sobre los problemas cruciales que estas aplicaciones plantean para la sociedad (Simoneaux 2001). Además, trabajos como el de Domènech-Casal (2017) proponen un marco didáctico en cuatro etapas (presentación del dilema; lectura; debate por parte del alumnado; y escritura de un ensayo) para la mejora de la argumentación en el aula.

\section{Objetivos de la investigación}

Considerando las aportaciones de la revisión bibliográfica, en este estudio se plantea el alcance de dos objetivos principales que son:

Objetivo 1. Analizar cuáles son los conocimientos y actitudes de un grupo de estudiantes de $2^{\circ}$ de Bachillerato acerca de las aplicaciones de la biotecnología, tratando de modo especial la biofarmacología.

Objetivo 2. Analizar de qué manera se basa en sus conocimientos y qué aspectos valora una muestra de estudiantes de $2^{\circ}$ de Bachillerato para justificar sus opiniones y tomar estos aspectos como referencia para plantear una propuesta de actividad de enseñanza.

\section{Metodología}

En los siguientes apartados se recogen las características de la investigación que presentamos.

\section{Población y muestra objeto de estudio}

En la primera parte del estudio han participado 184 estudiantes (16-18 años) de $2^{\circ}$ de Bachillerato (2B en adelante) de la modalidad científica y elección de la materia optativa Biología, pertenecientes a una muestra incidental de diferentes institutos de Educación Secundaria (IES), con distinto entorno demográfico (Tabla 1).

Tabla 1. Distribución por centro del alumnado participante

\begin{tabular}{|c|c|l|}
\hline Centro & Alumnado & Ubicación \\
\hline 1 & $\mathrm{n}=50$ & Centro urbano de ciudad mediana (capital de provincia) \\
\hline 2 & $\mathrm{n}=48$ & Centro urbano de ciudad mediana (capital de provincia) \\
\hline 3 & $\mathrm{n}=30$ & Ubicación en entorno rural \\
\hline 4 & $\mathrm{n}=19$ & Ubicación en entorno rural \\
\hline 5 & $\mathrm{n}=13$ & Periferia de ciudad mediana (capital de provincia) \\
\hline 6 & $\mathrm{n}=24$ & Centro de ciudad pequeña \\
\hline
\end{tabular}

En la segunda parte del estudio han participado 10 de los estudiantes anteriores, que fueron seleccionados de los distintos centros. 


\section{Diseño de los instrumentos de recogida de información y realización de las entrevistas}

Para dar respuesta al objetivo 1, se diseñó un cuestionario escrito que tuvo como referencia los antecedentes analizados referidos en este trabajo, así como las orientaciones curriculares de la materia Biología de 2B en el sistema educativo español, habiendo aspectos relacionados con la biotecnología en cuatro de los cinco bloques de contenidos, según se recoge en el Real Decreto 1105/2014 (Ministerio de Educación, Cultura y Deporte 2015). Este cuestionario inicial, estaba diferenciado en cuanto al conocimiento y la actitud de aplicaciones en biotecnología, en los ámbitos médico, alimentario, agropecuario, industrial y medioambiental. Además, fue ensayado en un estudio piloto mediante entrevistas individuales a 12 estudiantes de distintos centros y rendimiento académico. Los resultados aconsejaron suprimir alguna pregunta demasiado compleja, modificar el lenguaje y la estructura de otras y ajustar el tiempo de su realización a una duración de 30-35 minutos. El cuestionario final (Anexo I) consta de 3 preguntas, siendo el objetivo de las dos preguntas iniciales averiguar el grado de conocimiento de algunas aplicaciones biotecnológicas. En la primera, se presenta una tabla con diferentes aplicaciones teniendo el alumnado que señalar su grado de conocimiento sobre las mismas, así como aportar su significado; en la segunda, hay una tabla con 5 afirmaciones, algunas de ellas obtenidas de bibliografía revisada y otras planteadas por los investigadores, para que fueran señaladas como verdadera o falsa o no sabe/no contesta, para cada una de ellas. En cuanto a las cuestiones que tienen como objetivo identificar la actitud hacia la biotecnología, se presentaban 12 ítems sobre las aplicaciones en diferentes ámbitos en los que el alumnado tenía que marcar, en una escala tipo Likert, su grado de acuerdo, siendo 1 totalmente en desacuerdo y 5 totalmente de acuerdo. El cuestionario fue administrado a estudiantes que ya habían estudiado algunos conceptos relacionados con biotecnología, a finales del curso académico 2016/2017.

Para el objetivo 2 de la investigación, se seleccionó la aplicación de producción de proteínas para su uso como hormonas mediante ingeniería genética (biofarmacología). Esta aplicación fue elegida debido a que los resultados del análisis del cuestionario y la bibliografía consultada apuntaban a que el ámbito de la salud era uno de los más conocidos y mejor valorados por el alumnado. Se buscaron textos y artículos de divulgación científica relacionados con esta temática y destinados al público en general, pero con rigor en el vocabulario empleado y tratamiento de la información, y que, a su vez, pudieran resultar fáciles de comprender. Se elaboró un guion semiestructurado, que fue validado por profesores con experiencia (se sugirió eliminar o cambiar la redacción de alguna cuestión y añadir alguna imagen más aclaratoria) y se llevó a cabo una prueba piloto con estudiantes de $2 \mathrm{~B}$ de otros centros, que dio lugar a las entrevistas definitivas tras comprobar que se comprendían bien los textos y las preguntas formuladas. Estas entrevistas se realizaron a finales del curso académico 2016/2017, con posterioridad al cuestionario referido, y tenían una duración de 10 a 15 minutos. En las mismas, se presentaba un texto de ambientación, junto a diversos dibujos representando células, bacterias y ADN, en los que se explicaba cómo se produce actualmente la insulina. Las cuestiones inicialmente previstas indagaban sobre el conocimiento de esta tecnología y sus opiniones sobre el uso de la misma.

\section{Análisis de los resultados}

En la primera pregunta referente al conocimiento, se han clasificado las declaraciones en 3 códigos, teniendo en cuenta la auto percepción que el alumnado refiere sobre el término indicado (1-nunca lo he oído-, 2-lo he oído pero no sé qué significa- y 3-lo he oído y sé lo que significa-) y, también, la definición que proporcionaban, como incorrecta, correcta o no respondida. Para el análisis de la segunda pregunta sobre conocimiento, se calculó el porcentaje de estudiantes que respondía adecuadamente. En la parte referente a la actitud, se 
emplearon los valores aportados por cada estudiante en la escala tipo Likert, siendo estos 1, 2, 3, 4 o 5 (distribuidos desde 1 totalmente en desacuerdo a 5 totalmente de acuerdo para cada una de las afirmaciones). Esta codificación se introdujo en el programa de análisis estadístico SPSS en su versión 20.0 y se hallaron medias aritméticas y desviaciones típicas.

Para el análisis de la entrevista, se ha considerado la metodología propuesta por Christenson y Chang (2014) inspirada en la de Chang y Rundgren (2010) y Chang y Chiu (2008) pero de manera simplificada para su uso en el aula. Las autoras de dicho estudio emplearon dos componentes principales relacionados con aspectos estructurales del argumento, que son la afirmación (decisión) y las justificaciones que se declaran a favor (pros) y en oposición (contra) de las propias afirmaciones. Esta justificación puede consistir en declaraciones de conocimiento, cuando quienes argumentan usan contenidos disciplinares para respaldar sus afirmaciones, y/o de valor, cuando expresan su sensibilización moral o ética sobre el tema.

Dentro de la justificación con conocimiento, hay tres modalidades, "A" (conocimiento de contenido incorrecto, que también se ha empleado para quienes que no contestaban nada), "B" (conocimiento general no específico) o "C" (conocimiento correcto y relevante). A su vez, la categoría de valor puede subdividirse en dos, que son "no fundamentado" (respuesta simple que no va más allá de lo personal) o "fundamentado" (el o la estudiante expone un juicio y muestra un entendimiento amplio acerca de las consecuencias a largo plazo del punto de vista elegido y en gran escala), según el modelo anteriormente comentado de Christenson y Chang (2014). En nuestro trabajo hemos incluido una concreción de la categoría de valor fundamentado según en base a qué está hecha la fundamentación: "salud", "económico", "ambiental", "ético" o "desarrollo científico".

Se ha empleado el programa de análisis de datos cualitativos Atlas.ti para realizar una codificación provisional recogida en cada entrevista, siguiendo el modelo propuesto por otros investigadores de nuestra área (Martínez-Chico, Jiménez-Liso, López-Gay y Lucio-Villegas 2014), mediante los códigos empleados. Posteriormente, los tres autores de este trabajo, actuando de forma independiente, agruparon por semejanzas los códigos generados obtenidos provisionalmente en cada entrevista obteniendo un consenso inicial en la asignación a las categorías propuestas del $71.3 \%$. La discusión, aclaración de las discrepancias y consenso final con las definiciones de cada una de las categorías permitió el acuerdo completo.

\section{Resultados}

A continuación se describen los resultados obtenidos en este estudio, distribuidos en varias secciones. La primera parte comprende los dos apartados en los que se analizan cuáles son los conocimientos y actitudes que el alumnado presenta sobre diferentes aspectos de la biotecnología (objetivo 1), mientras que en la segunda se detallan qué conocimientos y valores son utilizados para justificar sus afirmaciones cuando argumentan sobre biofarmacología (objetivo 2).

\section{Primera parte: a) Conocimiento sobre aplicaciones en biotecnología}

Como se muestra, las aplicaciones que menos y peor describe el alumnado que respondió al cuestionario son el diagnóstico molecular preventivo, la terapia génica y las relacionadas con el uso de la biotecnología en la industria. Las aplicaciones que mejor se reconocían y describían eran las relacionadas con los alimentos transgénicos y la utilización de pruebas de ADN en ciencias forenses. El tratamiento de residuos por biorremediación y los procesos de fermentación son otras dos aplicaciones en las que hay un número importante de estudiantes que no conocen suficientemente. Destaca la comprensión insuficiente del proceso de 
fermentación a pesar de ser uno de los términos recogidos ampliamente en el currículo de $2 \mathrm{~B}$ (Tabla 2).

Tabla 2. Grado de conocimiento sobre las aplicaciones preguntadas

\begin{tabular}{|c|c|c|c|c|c|c|}
\hline \multirow{2}{*}{ Identificación de aplicaciones y significado } & \multicolumn{3}{|c|}{$\begin{array}{l}\text { Autopercepción de } \\
\text { conocimiento }\end{array}$} & \multicolumn{3}{|c|}{ Declaración } \\
\hline & 1 & 2 & 3 & Incorrecta & Correcta & $\begin{array}{l}\mathrm{NS} / \\
\mathrm{NC}\end{array}$ \\
\hline Diagnóstico molecular preventivo & 82 & 58 & 41 & 39 & 63 & 79 \\
\hline Terapia génica & 56 & 59 & 66 & 33 & 80 & 68 \\
\hline Fermentación para producción de alimentos & 16 & 76 & 88 & 53 & 69 & 58 \\
\hline Alimentos transgénicos & 6 & 37 & 138 & 55 & 104 & 22 \\
\hline $\begin{array}{l}\text { Utilización de plantas o bacterias en } \\
\text { industria }\end{array}$ & 34 & 77 & 65 & 39 & 51 & 86 \\
\hline $\begin{array}{l}\text { Utilización de microorganismos para } \\
\text { tratamiento de residuos }\end{array}$ & 45 & 52 & 82 & 23 & 88 & 68 \\
\hline Pruebas de ADN en ciencias forenses & 17 & 48 & 113 & 24 & 115 & 39 \\
\hline
\end{tabular}

Nota: Se reflejan la autopercepción del alumnado acerca de los términos preguntados (1-nunca lo he oído-, 2-lo he oído pero no sé qué significa- y 3-lo he oído y sé lo que significa-) y la adecuación o no de las definiciones que aportaban, codificando la declaración como incorrecta, correcta o no respondida. El número de estudiantes que faltan, hasta 184 del total, corresponde a quienes no contestaron nada para esas aplicaciones tanto en la autopercepción como en la declaración.

$\mathrm{Al}$ analizar los resultados acerca de la valoración de diversas afirmaciones sobre biotecnología basadas en sus fundamentos genéticos (Tabla 3), observamos que, entre nuestro alumnado, se dan algunas ideas erróneas que pueden condicionar su aprendizaje en esta materia.

Tabla 3. Conocimientos básicos sobre genética para comprender la biotecnología

\begin{tabular}{|l|c|}
\hline Afirmación (respuesta correcta) & $\begin{array}{c}\text { Responden } \\
\text { correctamente }(\%)\end{array}$ \\
\hline $\begin{array}{l}\text { a. El análisis de los genes de un individuo (screening genético) puede ayudar a saber a } \\
\text { qué enfermedades será más propenso (V) }\end{array}$ & 91.3 \\
\hline $\begin{array}{l}\text { b. Sólo los microorganismos genéticamente modificados pueden producir antibióticos } \\
\text { (F) }\end{array}$ & 67.4 \\
\hline $\begin{array}{l}\text { c. Las plantas transgénicas tienen genes, pero no tienen genes las plantas no } \\
\text { transgénicas (F) }\end{array}$ & 81.5 \\
\hline $\begin{array}{l}\text { d. No es posible transferir genes de una especie a otra (F) } \\
\text { e. La biorremediación mediante microorganismos genéticamente modificados capaces } \\
\text { de eliminar materiales que son difíciles de degradar naturalmente es un método de } \\
\text { descontaminación utilizado por ejemplo en derrames de petróleo (V) }\end{array}$ & 60.3 \\
\hline
\end{tabular}

Nota: Se indica entre paréntesis la respuesta correcta de las afirmaciones por las que se preguntó y se muestra el porcentaje de los y las estudiantes que respondieron adecuadamente. 
Debemos destacar que alrededor del 30\% de estudiantes que se encuentra en el nivel académico de $2 \mathrm{~B}$ cree que solo los microorganismos modificados genéticamente producen antibióticos o desconoce que es posible transferir genes de una especie a otra, aspectos que van a influir notablemente en la comprensión de la aplicación biofarmacología, sobre la que se profundizará en la segunda parte de los resultados. Además, no se debe obviar el casi $20 \%$ de nuestra muestra de estudiantes que opina que solamente tienen genes las plantas transgénicas (similar a lo detectado en otros trabajos para la población general, como el Eurobarómetro elaborado por Gaskell et al. 2006). Por otra parte, cerca del $40 \%$ del alumnado que realizó el cuestionario no respondió de manera adecuada a la afirmación sobre biorremediación.

\section{Primera parte: b) Valoración de diferentes aplicaciones de la biotecnología}

Como se observa en la Tabla 4, en el ámbito de la medicina, el diagnóstico molecular preventivo y la terapia génica son valorados positivamente, mientras que la aceptación de la modificación genética de animales para el estudio de enfermedades humanas es bastante inferior, cuando no rechazada abiertamente, coincidiendo con las conclusiones de otros trabajos, como el citado de Sáez et al. (2008). El uso de la biotecnología en la industria para la producción de fármacos es un tipo de aplicación muy aceptada, a pesar de que no era de las más conocidas. Por otra parte, aunque no se rechaza la biotecnología que se desarrolla para la producción de nuevos cosméticos, plásticos y otros productos, tampoco se valora especialmente, otorgándole más bien un papel de poca importancia para justificar investigaciones científicas.

En el ámbito de la alimentación, encontramos que el uso de la fermentación es valorado favorablemente, pero menos la obtención de transgénicos. Es más, si la manipulación genética tuviera como finalidad aumentar el valor nutricional del alimento, tendría mayor aceptación que si esta manipulación fuera para conseguir vegetales con mejores características comerciales o mayor cantidad de alimentos animales, aspecto que coincide con lo detectado por otros trabajos como Jurkiewicz et al. (2014). En cuanto a aplicaciones biotecnológicas diseñadas para la solución de problemas ambientales, nuestro alumnado se muestra muy favorable hacia el uso de microorganismos para el tratamiento de residuos mediante la biorremediación, sin embargo, son más reticentes al uso de biocombustibles. 
Tabla 4. Actitud hacia diferentes aplicaciones de la biotecnología

\begin{tabular}{|c|c|c|c|c|}
\hline \multicolumn{3}{|l|}{ Aplicaciones } & Media & Desviación típica \\
\hline \multirow{3}{*}{ Medicina } & \multicolumn{2}{|c|}{$\begin{array}{l}\text { Diagnóstico molecular preventivo: para ver a qué enfermedades } \\
\text { puede ser susceptible una persona en el futuro }\end{array}$} & 4.4 & 1.03 \\
\hline & \multicolumn{2}{|c|}{$\begin{array}{l}\text { Terapia génica: alteración de genes en células tisulares humanas } \\
\text { para tratar enfermedades }\end{array}$} & 4.1 & .98 \\
\hline & \multicolumn{2}{|c|}{$\begin{array}{l}\text { Modificar genéticamente animales para estudio de enfermedades } \\
\text { humanas }\end{array}$} & 2.9 & 1.29 \\
\hline \multirow{5}{*}{ Alimentación } & \multicolumn{2}{|c|}{$\begin{array}{l}\text { Fermentación: utilizar bacterias y levaduras en producción de } \\
\text { yogurt, pan, etc. }\end{array}$} & 4.4 & .93 \\
\hline & \multirow{4}{*}{$\begin{array}{l}\text { Alimentos } \\
\text { transgénicos }\end{array}$} & $\begin{array}{l}\text { Modificar levaduras para obtener mejor sabor } \\
\text { del pan }\end{array}$ & 3.3 & 1.24 \\
\hline & & $\begin{array}{l}\text { Modificar animales para obtener alimentos en } \\
\text { mayor cantidad o con características } \\
\text { modificadas (carne, leche) }\end{array}$ & 2.5 & 1.30 \\
\hline & & $\begin{array}{l}\text { Objetivo nutricional: producción de variedades } \\
\text { vegetales genéticamente modificadas como el } \\
\text { arroz dorado }\end{array}$ & 3.6 & 1.19 \\
\hline & & $\begin{array}{l}\text { Objetivo comercial: cultivar vegetales } \\
\text { genéticamente modificados con mejor aspecto, } \\
\text { maduración tardía, etc. }\end{array}$ & 2.7 & 1.40 \\
\hline \multirow{2}{*}{ Industria } & \multicolumn{2}{|c|}{$\begin{array}{l}\text { Producción de cosméticos, plásticos o combustibles utilizando } \\
\text { plantas o bacterias }\end{array}$} & 3.3 & 1.14 \\
\hline & \multicolumn{2}{|c|}{$\begin{array}{l}\text { Utilización de fármacos, vacunas y hormonas obtenidos mediante } \\
\text { procesos de ingeniería genética }\end{array}$} & 4.6 & .76 \\
\hline \multirow[t]{2}{*}{$\begin{array}{l}\text { Medio } \\
\text { ambiente }\end{array}$} & \multicolumn{2}{|c|}{$\begin{array}{l}\text { Uso de biocombustibles (combustibles para motores de explosión } \\
\text { o combustión elaborados a partir de materia prima de origen } \\
\text { biológico o renovable) en lugar de los combustibles actuales en un } \\
\text { futuro próximo }\end{array}$} & 2.7 & 1.31 \\
\hline & \multicolumn{2}{|c|}{ Uso de microorganismos en tratamiento de residuos } & 4.0 & 1.11 \\
\hline
\end{tabular}

Nota: Medias de las actitudes de los estudiantes según escala Likert de 1 (totalmente en desacuerdo) a 5 (totalmente de acuerdo) para cada aplicación y la desviación típica para estas medias.

\section{Segunda parte: Entrevistas individuales semiestructuradas sobre biofarmacología}

Nos centramos, a continuación, en la manera en la que el alumnado explica sus puntos de vista sobre el uso de la biofarmacología, analizando, para ello, la calidad del conocimiento científico utilizado, los valores en los que se asienta la opinión y si, en la argumentación, hay justificaciones a favor y en contra de su utilización. En el texto siguiente, se acompaña la exposición de resultados con algunas transcripciones de las entrevistas, indicando entre paréntesis los códigos asignados. 
Como especificamos en el apartado de análisis de resultados, se clasificarán en función del conocimiento empleado (desde $\mathrm{A}$ incorrecto a $\mathrm{C}$ correcto y relevante) y del valor mencionado (si es fundamentado, indicando en qué valor se fundamenta, o no fundamentado). En el Anexo II se recoge el número de códigos de cada tipo que fueron asignados al analizar cada una de las respuestas, aportando así una visión general de los criterios aportados para justificar sus decisiones en la argumentación.

En primer lugar, preguntamos si la insulina obtenida por ingeniería genética es igual a la humana. En nuestra reducida muestra de estudiantes, las respuestas se distribuyen prácticamente por igual, entre quienes piensan que esta insulina sí lo es o lo contrario. Para analizar las justificaciones estudiamos el conocimiento utilizado. Así, observamos planteamientos incorrectos como que la insulina bacteriana puede llevar alguna modificación respecto a la humana (conocimiento A). En otros casos se considera que la insulina sería idéntica a la humana, si bien una minoría (3 estudiantes de 10) aporta un conocimiento correcto y relevante (C) en su explicación. Por otra parte, aunque el valor en el que se sustentan las respuestas es, mayoritariamente, el del desarrollo científico (6 de 10) al referirse a técnicas biotecnológicas, también hay algunos casos sin fundamentación alguna (3 de 10). A continuación, se muestra un ejemplo de la codificación de la respuesta de un estudiante.

Pregunta 1 (P1): Esta insulina, ¿será exactamente igual a la de los bumanos o estará modificada, ya que la produce una bacteria?

Estudiante 3 (E3): No creo que sea idéntica a la bumana, porque tiene una de parte del gen de la bacteria y podría llevar cosas de la bacteria (en contra de la aplicación-conocimiento código A- valor, desarrollo científico).

Al preguntar si consideran peligroso tomar la insulina producida por las bacterias, aunque la totalidad se muestra a favor de hacerlo, 4 de 10 estudiantes consideran que la acción podría implicar riesgos para nuestra salud porque la insulina producida mediante ingeniería genética no sería tan efectiva como la humana o porque podría transmitir enfermedades a las personas. Por otra parte, 2 de 10 estudiantes mencionan, que probablemente, sería segura y que no tendría contraindicaciones porque es una práctica habitual.

\section{P2: ¿Consideras peligroso que la molécula de insulina proceda de procesos de ingeniería genética?}

E8: No lo veo peligroso siempre que se extraiga solo la insulina, si con la bacteria viniera algo más sería peligroso (pro-B-salud).

Acerca de si preferirían tomar insulina de una bacteria antes que otra fabricada por un animal, como por ejemplo un cerdo, apreciamos que la mayoría elige la insulina obtenida de las bacterias ( 9 pros y 1 indefinido). Parece que quienes optan por la de bacteria lo hacen porque conocen que es obtenida por ingeniería genética y, por lo tanto, igual a la humana, o porque consideran que la de los animales puede suponer una explotación inadecuada de estos, prefiriendo, por tanto, la procedencia de un microorganismo.

\section{P3: ¿Es mejor tomar insulina que produce una bacteria que insulina que procede de un cerdo, por ejemplo?}

E7: Yo creo que la que viene de la bacteria porque le has introducido el gen de la humana, será más parecida (proB-desarrollo científico).

E9: No sería muy ético comprar insulina procedente de seres bumanos ni animales... pero de bacterias, pese a ser un ser vivo, no genera tanto problema ético y moral (pro-B-ético).

Si bien la mayor parte del alumnado es partidario de modificar el genoma bacteriano para obtener insulina (9 de 10), al analizar la calidad de sus justificaciones observamos que no utilizan un conocimiento científico elaborado (5 respuestas calificadas A y solo $3 \mathrm{C}$ ). El valor en el que sustentan sus juicios es la salud (6 de 10), seguido de aspectos éticos (4 de 10). En una de las 
ocasiones, el valor moral se emplea para proponer controles éticos de las investigaciones del ADN humano.

P4: ¿Qué opinión tienes acerca de la necesidad de modificar los genes de una bacteria para producir una hormona deseada como la insulina?

E9: Me parece algo bueno porque estamos investigando en evitar problemas que boy en la sociedad son bastantes influyentes como el de la diabetes (pro-C-Salud)... Pero, por ejemplo, con la terapia génica, se tiene miedo de que se juegue tanto con el ADN bumano que se pueda llegar a cambiar y crear una especie nueva (contra-Bético).

En general, nuestro alumnado reconoce ventajas de esta técnica y, sobre todo, citan la posibilidad de mejorar la vida de las personas afectadas de diabetes, produciendo insulina en grandes cantidades, lo cual resulta adecuado desde el punto de vista del conocimiento (6 respuestas $\mathrm{C}$ ).

P5: ¿Podrías indicar algunas ventajas de esta técnica?

E6: Obtener insulina en grandes cantidades (pro-C-salud-económico).

P6: ¿Podrías indicar algunos inconvenientes de esta técnica?

E9: Que pueda llegarse a jugar con el acervo genético que cambiásemos de especie (contra-B-ambiental).

En cuanto a las justificaciones en contra se encuentra, como vemos, algún reparo por errores en la técnica que produjeran una insulina defectuosa o por límites morales o ambientales a las investigaciones.

\section{Conclusiones e implicaciones educativas}

A lo largo de este trabajo, hemos analizado las dificultades de una muestra de estudiantes de 2B para comprender aspectos básicos de la biotecnología y las principales aplicaciones biotecnológicas, así como la utilización de su conocimiento y qué valores tienen en cuenta a la hora de justificar sus posiciones personales sobre una aplicación biofarmacológica, como es la ingeniería genética para obtener insulina.

De acuerdo con el objetivo 1, constatamos que nuestro alumnado tiene dificultades en aspectos básicos de genética o microbiología que interfieren en su comprensión de la biotecnología y sus aplicaciones. Así, hemos encontrado un porcentaje significativo que considera que las plantas no tienen genes (aunque sí las transgénicas) o que no es posible transferir genes de un ser vivo a otro. Estos resultados coinciden otros estudios en nuestro país y en otros contextos diferentes (AbuQamar et al. 2015, de la Vega et al. 2018, Gaskell et al. 2006, Ruiz, Banet y López-Banet 2017b). Asimismo, también hemos identificado otros errores como que solo los microorganismos modificados genéticamente producirían antibióticos o el desconocimiento de su papel en la biorremediación.

Además, hemos comprobado la existencia de posiciones favorables hacia la utilización de aquellas aplicaciones que están relacionadas con la medicina y la salud (coincidiendo con otros trabajos de Öztürk-Akar 2016, Occelli et al. 2011, Fonseca et al. 2012 y Sáez et al. 2008). En este ámbito, se suele aceptar la utilización de microorganismos en las investigaciones biotecnológicas y rechazar la manipulación genética de animales en la experimentación (coincidiendo con Dawson y Schibeci 2003). En nuestro trabajo, también hemos identificado la baja aceptación de la manipulación de vegetales y animales para la obtención de mejoras comerciales en los alimentos y, en algunos casos, la necesidad de disponer de límites éticos para los trabajos en biotecnología, incluso en la medicina. A modo de resumen, en relación con los factores que influyen en la actitud hacia el uso de distintas aplicaciones biotecnológicas, consideramos que nuestro alumnado es dependiente de, al menos tres 
factores: la utilidad de la misma (salud, económica, alimentación, ambiental, desarrollo científico), los organismos vivos implicados en las investigaciones y las limitaciones éticas o ambientales relacionadas con consecuencias de las manipulaciones genéticas.

Por otra parte, en cuanto a nuestro objetivo 2 , hemos puesto a prueba una estrategia para el análisis de las justificaciones (Christenson y Chang 2014), a través del análisis de entrevistas a una muestra reducida de estudiantes de $2 \mathrm{~B}$, acerca del uso de la ingeniería genética para obtener insulina. Como se ha señalado en el análisis de los resultados, el modelo de análisis se ha basado en las posiciones a favor y en contra, en la calidad del conocimiento específico empleado y en los valores que sustentaban sus afirmaciones. En este aspecto, hemos constatado la escasa frecuencia de utilización de un conocimiento científico adecuado y relevante para el establecimiento de sus posiciones, lo cual vuelve a reflejar la necesidad de mejorar ese conocimiento básico para comprender la biotecnología, así como el uso del mismo en sus planteamientos personales. Por otra parte, comprobamos que estas justificaciones sobre el uso de la ingeniería genética se han basado con frecuencia en el valor "salud", especialmente al mostrarse a favor, aunque también se han utilizado otros valores como el de "desarrollo científico", para sus posibilidades futuras, y el "ético", a la hora de rechazar a los animales para su producción. Asimismo, también evidenciamos la escasa frecuencia con la que nuestro alumnado ha valorado simultáneamente los aspectos positivos y negativos para justificar sus opiniones.

De cara a las consecuencias de nuestro trabajo en el aula, debemos señalar que el estudio de la biotecnología en el Bachillerato debe basarse en un conocimiento adecuado de aspectos de genética (localización de la información hereditaria, transmisión de la información o expresión genética), además de otros relacionados con las características de los microorganismos. Por ello, se debe profundizar en la enseñanza de estos contenidos para que se puedan comprender mejor los fundamentos de las distintas aplicaciones biotecnológicas, establecer opiniones correctamente formadas acerca del uso de las mismas y formular argumentos basados en pruebas. En este sentido, de acuerdo con el trabajo de Simonneaux y Chouchane (2011), la utilización de las CSC en situaciones auténticas, como puede ser la producción de fármacos por ingeniería genética, puede ser un contexto escolar adecuado para mejorar la calidad argumentativa de nuestro alumnado, al propiciar el uso del conocimiento científico.

Finalmente, consideramos que los resultados de las entrevistas sobre biofarmacología, en las que hemos analizado sus justificaciones a favor o en contra, los conocimientos empleados y los valores utilizados, pueden ser tomadas como referencia, tanto por el profesorado de Biología como en la formación de profesorado de educación secundaria, para la elaboración de actividades. En el Anexo III se presenta una adaptación para el aula de Bachillerato de la entrevista sobre la producción de insulina siguiendo el marco didáctico propuesto por Domènech-Casal (2017). En relación a la biofarmacología, podríamos relacionar el dilema con la elaboración de insulina por bacterias, para trabajar en pequeños grupos. La lectura se realizaría sobre el texto de la actividad y otras referencias que aborden el uso de la biotecnología, destacando aspectos favorables y contrarios. A continuación, se procedería a introducir un debate, en primer lugar en pequeños grupos de estudiantes y, posteriormente, con toda la clase. Tras esto, se procedería a la redacción de un ensayo en el que se abordasen las posiciones personales sobre si utilizarían esta tecnología, estableciendo los conocimientos científicos implicados, planteando aspectos a favor y en contra, así como identificando los valores (salud, económico, ambiental, ético o desarrollo científico) en los que se sustentan.

En nuestra opinión, de acuerdo con los resultados presentados en este trabajo, este tipo de actividades de enseñanza basadas en CSC en situaciones reales, con el desarrollo del marco metodológico propuesto, pueden facilitar la participación del alumnado en debates de un 
modo adecuado y crítico al reflexionar sobre la importancia del uso del conocimiento científico, la variedad de posiciones posibles o los valores que respaldan los argumentos empleados. Consideramos de interés seguir profundizando en este tipo de propuestas didácticas, que pueden resultar de utilidad para la formación del profesorado como recurso para ser desarrollado en las aulas de Bachillerato. En futuros estudios, la puesta en práctica de estrategias metodológicas y nuevas actividades concretas, como la presentada, permitiría contribuir a mejorar y continuar progresando en la Didáctica de las Ciencias Experimentales.

\section{Agradecimientos}

Los autores agradecen el proyecto PGC2018-097988-A-I00 financiado por: FEDER / Ministerio de Ciencia e Innovación (MCI) de España-Agencia Estatal de Investigación (AEI).

\section{Referencias bibliográficas}

AbuQamar S., Alshannag Q., Sartawi A. e Iratni R. (2015) Biotechnology Education Educational Awareness of Biotechnology Issues among Undergraduate Students at the United Arab Emirates University. Biochemistry and Molecular Biology Education, 43(4), 283-293. http:/ / doi.org/10.1002/bmb.20863

Bravo B. y Jiménez-Aleixandre M. P. (2014) Articulación del uso de pruebas y el modelo de flujo de energía en los ecosistemas en argumentos de alumnado de Bachillerato. Enseñanza de Las Ciencias, 32(3), 425-442. http://doi.org/http://dx.doi.org/10.5565/rev/ensciencias.1281

Chang S. N. y Chiu M. H. (2008) Lakatos' scientific research programmes as a framework for analysing informal argumentation about socio-scientific issues. International Journal of Science Education, 30(13), 1753-1773.

Chang Rundgren S. N. y Rundgren C. J. (2010, April) SEE-SEP: From a separate to a holistic view of socioscientific issues. En Asia-Pacific Forum on Science Learning \& Teaching (Vol. 11, No. 1).

Chen S. Y., Chu Y. R., Lin C. Y. y Chiang T. Y. (2016) Students' knowledge of, and attitudes towards biotechnology revisited, 1995-2014: Changes in agriculture biotechnology but not in medical biotechnology. Biochemistry and Molecular Biology Education, 44(5), 475-491. http://doi.org/10.1002/bmb.20969

Christenson N. (2015) Socioscientific argumentation: Aspects of content and structure. Karlstads universitet.

Christenson N. y Chang Rundgren S. N. (2014) A framework for teachers' assessment of socio-scientific argumentation: an example using the GMO issue. Journal of Biological Education, 49(2), 204-212. http:/ / doi.org/10.1080/00219266.2014.923486

Dawson V. (2007) An exploration of high school (12-17 Year Old) students' understandings of, and attitudes towards biotechnology processes. Research in Science Education, 37(1), 5973.

Dawson V. y Schibeci R. (2003) Western Australian high school students' attitudes towards biotechnology processes. Journal of Biological Education, 38 (1), 1-6.

De la Vega-Naranjo M., Lorca-Marín A.A., De las Heras-Pérez M.A. (2018) Conocimientos y actitudes hacia la biotecnología en alumnos de último curso de Educación Secundaria Obligatoria. Revista Eureka sobre Enseñanza y Divulgación de las Ciencias 15(3), 3301. doi:10.25267/Rev_Eureka_ensen_divulg_cienc.2018.v15.i3.3301

Domènech-Casal J. (2017) Propuesta de un marco para la secuenciación didáctica de Controversias Socio-Científicas. Estudio con dos actividades alrededor de la genética. 
Revista Eureka sobre Enseñanza y Divulgación de las Ciencias, 14(3), 601-620. Recuperado de: http://hdl.handle.net/10498/19510

Fonseca M. J., Costa P., Lencastre L. y Tavares F. (2012) Multidimensional analysis of highschool students' perceptions about biotechnology, Journal of Biological Education, 46(3), 129-139

Gardner G. E. y Troelstrup, A. (2015) Students' Attitudes Toward Gene Technology: Deconstructing a Construct. Journal of Science Education and Technology, 24(5), 519-531. http://doi.org/10.1007/s10956-014-9542-4

Gaskell G., Stares S., Allansdottir A., Allum N., Corchero C., Fischler C. y Wolfgang W. (2006) Europeans and Biotechnology in 2005: Patterns and Trends.

Hammann M. (2018) Biotechnology. En K. Kampourakis y M. J. Reiss (Eds.), Teaching Biology in Schools Global Research, Issues, and Trends (First edit, pp. 192-201). New York: Routledge.

Jiménez-Aleixandre M. P., Bugallo Rodríguez A. y Duschl R. A. (2000) "Doing the Lesson " or "Doing Science ": Argument in High School Genetics. Science Education, 84(6), 757792.

Jiménez-Aleixandre M. P. y Erduran S. (2007) Argumentation in science education: An Overview. In S. Erduran y M. P. Jiménez-Aleixandre (Eds.), Argumentation in Science Education: Perspectives from Classroom-Based Research (pp. 3-29). Springer.

Jiménez-Aleixandre M.P. y Puig B. (2013) El papel de la argumentación en la clase de ciencias. Alambique, Didáctica de las Ciencias Experimentales, 75, 85-90.

Jurkiewicz A., Zagórski J., Bujak F., Lachowski S. y Luszczki M. F. (2014) Emotional attitudes of young people completing secondary schools towards genetic modification of organisms (GMO) and genetically modified foods (GMF). Annals of Agricultural and Environmental Medicine, 21(1), 205-211.

Kafarski P. (2012) Rainbow code of biotechnology. Chemik, 66(8), 814-816.

Maguregi González G., Uskola Ibarluzea A. y Burgoa Etxaburu B. (2017) Modelización, argumentación y transferencia de conocimiento sobre el sistema inmunológico a partir de una controversia sobre vacunación en futuros docentes. Enseñanza de Las Ciencias, 35(2), 29-50. http://doi.org/http://dx.doi.org/10.5565/rev/ensciencias.2237

Martínez Bernat F. X., García Ferrandis I. y García Gómez J. (2019) Competencias para mejorar la argumentación y la toma de decisiones sobre conservación de la biodiversidad. Enseñanza de Las Ciencias, 37(1), 55-70. http://doi.org/https://doi.org/10.5565/rev/ensciencias.2323

Martínez-Chico M., Jiménez-Liso M. R., López-Gay y Lucio-Villegas R. (2014) La indagación en las propuestas de formación inicial de maestros: análisis de entrevistas a los formadores de Didáctica de las Ciencias Experimentales (Model-based inquiry for preservice primary teacher training: science teacher educators' interview ana. Enseñanza de Las Ciencias, 32(3), 591-608. http://doi.org/10.5565/rev/ensciencias.1376

Ministerio de Educación Cultura y Deporte (2015) Real Decreto 1105/2014. Boletín Oficial Del Estado, Sec. I(Num. 3), 169-546.

Occelli M., Vilar M. T. y Valeiras N. (2011) Conocimientos y actitudes de estudiantes de la ciudad de Córdoba (Argentina) en relación a la Biotecnología. Revista Electrónica de Enseñanza de Las Ciencias, 10(3), 227-242. 
OCDE (2005) A framework, for Biotechnology Statistics, OECD Secretariat, Paris.

Öztürk-Akar E. (2016) Turkish university students' knowledge of biotechnology and attitudes toward biotechnological applications. Biochemistry and Molecular Biology Education, 1-11. http://doi.org/10.1002/bmb.20996

Prokop P., Lesková A., Kubiatko M. y Diran, C. (2007) Slovakian students' knowledge of and attitudes toward biotechnology. International Journal of Science Education, 29(7), 895-907.

Ruiz C., Banet E. y López-Banet L. (2017a) Conocimientos de estudiantes que inician el Bachillerato sobre nociones básicas de Genética y aplicaciones de la Biotecnología. Enseñanza de Las Ciencias, $n^{0}$ extraor, 1421-1428. Recuperado de https://ddd.uab.cat/record/184436? ln=ca

Ruiz C., Banet E. y López Banet L. (2017b) Conocimientos de los estudiantes de secundaria sobre herencia biológica: implicaciones para su enseñanza. Revista Eureka Sobre Enseñanz̧a Y Divulgación de Las Ciencias, 14(3), 550-569.

Sáez M., Gómez-Niño A. y Carretero A. (2008) Matching society values: Students' views of biotechnology. International Journal of Science Education, 30(2), 167-183. http://doi.org/10.1080/09500690601152386

Simonneaux L. (2002) Analysis of classroom debating strategies in the field of biotechnology, Journal of Biological Education, 37:1, 9-12, DOI: 10.1080/00219266.2002.9655839

Simonneaux L. y Chouchane H. (2011) The reasoned arguments of a group of future biotechnology technicians on a controversial socio-scientific issue: human gene therapy, Journal of Biological Education, 45(3), 150-157.

Usak M., Erdogan M., Prokop P. y Ozel M. (2009) High school and university students' knowledge and attitudes regarding biotechnology. Biochemistry and Molecular Biology Education, 37(2), 123-130. http://doi.org/10.1002/bmb.20267

Toulmin S. E. (2003) The uses of argument (Updated ed). Published in the United States of America by Cambridge University Press, New York. 


\section{Anexo I. Cuestionario sobre conocimientos y valoraciones de diferentes aplicaciones en biotecnología}

\section{A continuación, te presentamos un cuestionario con algunas preguntas relacionadas con aplicaciones} de la biotecnología. Por favor, indícanos:

Edad:

Curso Académico:

1. ¿Podrías explicar brevemente en qué consisten las siguientes aplicaciones? ¿Qué ventajas e inconvenientes piensas que pueden tener para las personas y/o la sociedad?

\begin{tabular}{|c|c|c|c|c|}
\hline Aplicaciones & $\begin{array}{l}\text { Grado de } \\
\text { conocimiento (nunca } \\
\text { la be oído, la he oído } \\
\text { pero no sé lo que } \\
\text { significa, la be oído y sé } \\
\text { lo que significa) }\end{array}$ & En qué consiste & Ventajas & Inconvenientes \\
\hline $\begin{array}{c}\text { Diagnóstico } \\
\text { molecular preventivo }\end{array}$ & & & & \\
\hline Terapia génica & & & & \\
\hline $\begin{array}{l}\text { Fermentación para } \\
\text { producción de } \\
\text { alimentos }\end{array}$ & & & & \\
\hline $\begin{array}{l}\text { Alimentos } \\
\text { transgénicos }\end{array}$ & & & & \\
\hline $\begin{array}{c}\text { Utilización de plantas } \\
\text { o bacterias en } \\
\text { industria }\end{array}$ & & & & \\
\hline $\begin{array}{c}\text { Utilización de } \\
\text { microorganismos } \\
\text { para tratamiento de } \\
\text { residuos }\end{array}$ & & & & \\
\hline $\begin{array}{c}\text { Pruebas de ADN en } \\
\text { Ciencias Forenses }\end{array}$ & & & & \\
\hline
\end{tabular}

2. Indica Verdadero (V), Falso (F) o No lo sé (NS) en las siguientes afirmaciones relacionadas con la biotecnología:

a) El análisis de los genes de un individuo (screening genético) puede ayudar a saber a qué enfermedades será más propenso.

b) Sólo los microorganismos genéticamente modificados pueden producir antibióticos.

c) Las plantas transgénicas tienen genes, pero no tienen genes las plantas no transgénicas.

d) No es posible transferir genes de una especie a otra.

e) La biorremediación mediante microorganismos genéticamente modificados capaces de eliminar materiales que son difíciles de degradar naturalmente es un método de descontaminación utilizado por ejemplo en derrames de petróleo.

3. Indica si estás de acuerdo con la puesta en práctica de las técnicas a las que se refieren las siguientes 
afirmaciones, siendo 1 totalmente en desacuerdo y 5 totalmente de acuerdo:

\begin{tabular}{|c|c|c|c|c|c|c|c|}
\hline \multicolumn{3}{|r|}{ Aplicaciones } & 1 & 2 & 3 & 4 & 5 \\
\hline \multirow{5}{*}{ Alimentación } & \multicolumn{2}{|c|}{$\begin{array}{l}\text { Fermentación: utilizar bacterias y levaduras en producción de } \\
\text { yogurt, pan, etc. }\end{array}$} & & & & & \\
\hline & \multirow{4}{*}{$\begin{array}{l}\text { Alimentos } \\
\text { transgénicos }\end{array}$} & $\begin{array}{l}\text { Modificar levaduras para obtener mejor sabor } \\
\text { del pan }\end{array}$ & & & & & \\
\hline & & $\begin{array}{l}\text { Modificar animales para obtener alimentos en } \\
\text { mayor cantidad o con características } \\
\text { modificadas (carne, leche) }\end{array}$ & & & & & \\
\hline & & $\begin{array}{l}\text { Objetivo nutricional: producción de variedades } \\
\text { vegetales genéticamente modificadas como el } \\
\text { arroz dorado }\end{array}$ & & & & & \\
\hline & & $\begin{array}{l}\text { Objetivo comercial: cultivar vegetales } \\
\text { genéticamente modificados con mejor aspecto, } \\
\text { maduración tardía, etc. }\end{array}$ & & & & & \\
\hline \multirow{3}{*}{ Medicina } & \multicolumn{2}{|c|}{$\begin{array}{l}\text { Diagnóstico molecular preventivo: para ver a qué enfermedades } \\
\text { puede ser susceptible una persona en el futuro }\end{array}$} & & & & & \\
\hline & \multicolumn{2}{|c|}{$\begin{array}{c}\text { Terapia génica: alteración de genes en células tisulares humanas } \\
\text { para tratar enfermedades }\end{array}$} & & & & & \\
\hline & \multicolumn{2}{|c|}{$\begin{array}{c}\text { Modificar genéticamente animales para estudio de enfermedades } \\
\text { humanas }\end{array}$} & & & & & \\
\hline \multirow{2}{*}{ Industria } & \multicolumn{2}{|c|}{$\begin{array}{l}\text { Producción de cosméticos, plásticos o combustibles utilizando } \\
\text { plantas o bacterias }\end{array}$} & & & & & \\
\hline & \multicolumn{2}{|c|}{$\begin{array}{c}\text { Utilización de fármacos, vacunas y hormonas obtenidos mediante } \\
\text { procesos de ingeniería genética }\end{array}$} & & & & & \\
\hline \multirow[t]{2}{*}{$\begin{array}{l}\text { Medio } \\
\text { ambiente }\end{array}$} & \multicolumn{2}{|c|}{$\begin{array}{l}\text { Uso de biocombustibles (combustibles para motores de explosión } \\
\text { o combustión elaborados a partir de materia prima de origen } \\
\text { biológico o renovable) en lugar de los combustibles actuales en un } \\
\text { futuro próximo }\end{array}$} & & & & & \\
\hline & \multicolumn{2}{|c|}{ Uso de microorganismos en tratamiento de residuos } & & & & & \\
\hline
\end{tabular}


Anexo II. Codificación de las entrevistas sobre biofarmacología

\begin{tabular}{|c|c|c|c|c|c|c|c|c|c|c|c|c|}
\hline \multirow{3}{*}{ Pregunta } & \multicolumn{3}{|c|}{ Justificación } & \multicolumn{3}{|c|}{$\begin{array}{l}\text { Conocimiento de } \\
\text { contenido }\end{array}$} & \multicolumn{6}{|c|}{ Valor } \\
\hline & \multirow[b]{2}{*}{ Pro } & \multirow[b]{2}{*}{$\begin{array}{c}\text { Con- } \\
\text { tra }\end{array}$} & \multirow[b]{2}{*}{$\begin{array}{l}\text { Indefi } \\
\text {-nida }\end{array}$} & \multirow[b]{2}{*}{ A } & \multirow[b]{2}{*}{ B } & \multirow[b]{2}{*}{$\mathrm{C}$} & \multirow{2}{*}{$\begin{array}{c}\text { No } \\
\text { funda- } \\
\text { mentado }\end{array}$} & \multicolumn{5}{|c|}{ Fundamentado } \\
\hline & & & & & & & & Salud & $\begin{array}{c}\text { Econó } \\
\text {-mico }\end{array}$ & $\begin{array}{c}\mathrm{Am}- \\
\text { bient } \\
\text { al }\end{array}$ & Ético & $\begin{array}{l}\text { Desa- } \\
\text { rrollo }\end{array}$ \\
\hline P1 & 4 & 5 & 1 & 4 & 3 & 3 & 3 & 1 & 0 & 0 & 0 & 6 \\
\hline P2 & 10 & 0 & 0 & 6 & 4 & 0 & 3 & 4 & 0 & 0 & 0 & 2 \\
\hline P3 & 9 & 0 & 1 & 1 & 5 & 4 & 0 & 4 & 1 & 0 & 1 & 3 \\
\hline P4 & 9 & 1 & 0 & 5 & 3 & 3 & 1 & 6 & 0 & 0 & 4 & 0 \\
\hline P5 & 9 & 0 & 1 & 1 & 2 & 6 & 0 & 8 & 1 & 0 & 0 & 1 \\
\hline P6 & 2 & 6 & 1 & 4 & 5 & 0 & 2 & 5 & 0 & 2 & 0 & 0 \\
\hline
\end{tabular}




\section{Anexo III. Insulina de laboratorio}

Leed el texto que te presentamos sobre cómo han cambiado las fuentes para la obtención de la insulina en personas diabéticas a lo largo de los años.

La insulina es una hormona producida por el páncreas que regula los niveles de glucosa en la sangre. Las personas diabéticas, no producen insulina, o lo hacen en muy pequeñas cantidades, por lo que deben administrarla de fuentes externas.

El proceso de fabricación de la insulina se fue perfeccionando y alrededor de los años ochenta las personas diabéticas usaban insulina que provenía de animales como cerdos o vacas. Pero esta insulina, aunque similar a la humana, no era exactamente la misma.

Más tarde, se descifró la estructura química de la insulina pero los científicos no tuvieron mucha suerte para producirla en grandes cantidades si sólo usaban procesos químicos.

Finalmente, por procesos de ingeniería genética, el gen de la insulina fue cortado, editado e introducido en la bacteria Escherichia coli. Nació así una pequeñísima fábrica de insulina, que se multiplicaba cada vez que se alimentaba la colonia bacteriana, produciendo luego miles de otras fábricas de las que brotaban ríos de insulina. Hoy, al igual que la cerveza, la insulina se obtiene por fermentación en tanques enormes llamados biorreactores.

Adaptado de: http://cienciaes.com/ciertaciencia/2014/10/01/insulina-y-biotecnologia/

Abora fijaos en la imagen que os presentamos y que mostraría el proceso por el cual se obtiene insulina bumana a partir de bacterias.

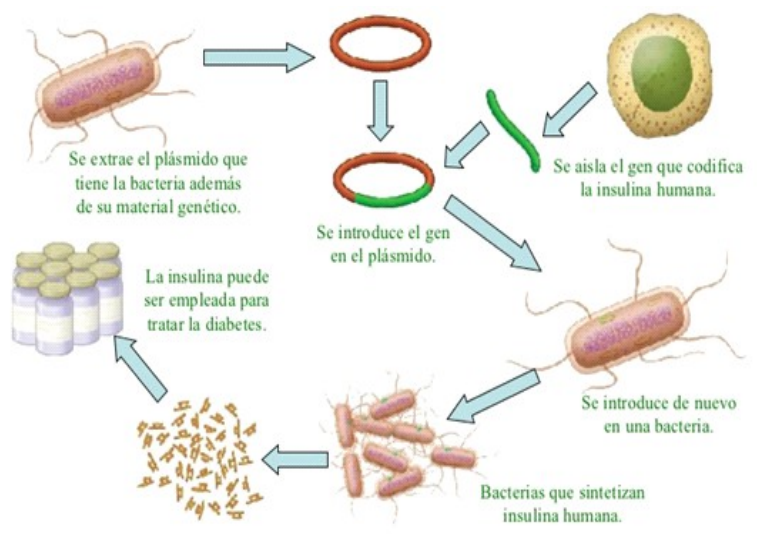

Primera parte. Trabajando en pequeños grupos, responded a las siguientes cuestiones. Revisad para ello el material complementario a vuestra disposición. Posteriormente, realizaremos una puesta en común para comprobar las respuestas:

1. Ayudándote de la imagen, ¿sabríais explicar de qué manera se obtiene insulina humana de una bacteria?

2. La insulina que se produce, ¿qué tipo de biomolécula es (glúcido, lípido, proteína, ácido nucleico...)?

3. ¿Qué proceso relaciona el ADN con las proteínas? Explicadlo brevemente.

4. Esta insulina ¿`será exactamente igual a la de los humanos o estará modificada, ya que la produce una bacteria?

Segunda parte. En primer lugar debatir en pequeños grupos las siguientes cuestiones. Posteriormente elegir un portavoz para plantear vuestras conclusiones al resto de la clase:

5. ¿Es mejor tomar insulina que produce una bacteria que insulina que procede de un cerdo, por ejemplo? ¿Por qué?

6. ¿Consideras peligroso que la molécula de insulina proceda de procesos de ingeniería genética?

7. ¿Podrías indicar algunas ventajas e inconvenientes de esta técnica?

Tercera parte. Redacta un texto (que posteriormente leerás) en el que expongas de forma ordenada tu opinión acerca de la pregunta que aparece en el recuadro. Ten en cuenta para ello, las consideraciones realizadas en la $\mathbf{1}^{\mathbf{a}}$ Parte para aclarar los aspectos científicos de la cuestión; 2) los aspectos a favor y en contra que pueda tener esta cuestión; y 3) En qué aspectos fundamentas tu decisión (aspectos de salud, económicos, éticos, ambientales, etc.). Para los puntos 2 y 3 , revisa lo señalado en la $2^{\mathbf{a}}$ Parte de la actividad.

hormona deseada como la insulina? 